\title{
La moral de cosmogénesis de Teilhard de Chardin
}

Todavía resuenan - serenados ya los ánimos de los años sesenta, en que era elevado a las más altas cumbres del pensamiento o lanzado a los más profundos abismos, condenado a la herejía o prenunciado como futuro Padre de la Iglesia - los ecos del homenaje rendido a Teilhard de Chardin por la Unesco en París el 18 de septiembre, en el centenario de su nacimiento, para agradecerle «el enriquecimiento que de sus trabajos han recibido la reflexión religiosa, filosófica y científica» y «para difundir su magna obra, rica en esperanza»'.

Este doble fin persiguen estas páginas: agradecer a Teilhard lo que de positivo hay en su visión dinámica de la moralidad con la exposición de esa misma moral.

Teilhard de Chardin había recibido una formación filosófica y teológica escolástica. Pero se liberó de las categorías formales, del lenguaje y de los esquemas de pensamiento de la Escuela, por su propio temperamento poéticocreador, que no soportaba moldes, y por su dedicación a la ciencia. Consecuencia de esa liberación es, en ocasiones, la falta de rigor terminológico y de justificación racional de sus afirmaciones -intuiciones y visiones sintéticas más que deducciones o análisis, sin que los excluya del todo-, aunque, en contrapartida, sus escritos tienen casi siempre la vivacidad, el encanto y la sugestión del poeta. Eso no quiere decir, ni que no hayan huellas de sus estudios filosófico-teológicos, ni que falte el rigor de su investigación científica, para la que estaba especialmente dotado por su águdo sentido de la observación y por un notable espíritu de síntesis.

Estas consideraciones son pertinentes en el tema de la moral. Por una parte se mantienen en la idea de la fundamentación metafísica de la moral. Pe-

1. Cfr. la reseña de este homenaje en Etudes, 355/5, 437-44. 
ro no habla con precisión y univocidad de esa metafísica, de la que pasa en ocasiones tan solemnes en su pensamiento como cuando escribe su Phénomène humain, mientras la incluye cuando hace balance de su posición intelectual, y en este caso como ciencia deductiva del ser, cuando en otros la propone como mera concepción del universo. Efectivamente, en su breve escrito, fechado en Pekín en 25 de abril de 1945, «La morale peut-elle se passer de soubassements metaphysiques avoués ou inavoués?» habla de la implicación necesaria de estos fundamentos metafísicos en toda moral. Era la doctrina tradicional de la Escuela ${ }^{2}$. «De por sí la moral y metafísica se presentan inevitablemente (por estructura) como las dos caras (intelectual y práctica) de un mismo sistema. Una metafísica se duplica necesariamente con una moral, y "recíprocamente. Cada metafísica genera su moral; y cada moral implica su metafísica. Moral y metafísica van esencialmente a la par. Tantas definiciones de bien y de mal, y tantas formas de obligación como soluciones dadas al mundo».

Sin embargo, a la hora de definir, en ese mismo escrito, esa metafísica la describe como una concepción del mundo más que como una ciencia racional del ser.

«Por metafísica es preciso entender aquí toda solución o visión del mundo (de la vida) 'as a Whohe' (toda Weltanschauung) sea que esta solución se imponga a la inteligencia, sea que uno se adhiera a ella categóricamente como a una opción o a un postulado» ${ }^{3}$.

Tres años más tarde, en 1948, cuando intenta una visión global de su pensamiento, la resume en tres partes: física o fenomenología, metafísica y mística. $Y$, aun reconociendo él mismo todo lo que de precario y provisional hay en ella, no renuncia a que su metafísica sea rigurosa reconstrucción deductiva de su fenomenología a partir del concepto de ser ${ }^{4}$.

2. Como ejemplo, he ahí las palabras de J. MARITAIN: «Hay necesidad absoluta de recurrir a la metafísica si queremos justificar la validez real, objetiva de las normas y de los valores morales». En base a ese presupuesto formula los conceptos fundamentales de la ética, e.d. los más cercanos a la metafísica: bien, valor, fin etc. Las nociones preliminares de la Filosofía moral. Club de Lectores. Buenos Aires 1966, p. 26.

En el mismo sentido se expresa R. Simón, Moral. Herder, Barcelona 1968 p. 9-10 y R. JoLIver, Morat. Ed. C. Lohle. Buenos Aires 1959, p. 37. Fr. Gregolre, Les grandes doctrines morales PUF $1964-4^{\mathrm{a}}$ aun cuando postula una metafísica como fundamento de toda moral, éste puede ser anterior (con lo que la moral sería una consecuencia y prolongación de la metafísica) o posterior (como respuesta al estímulo de una conciencia de sí misma a través de la reflexión metafísica) pp. 6-7. Sobre el problema de las relaciones de la ética y la metafísica puede consultarse ARANGUREN, J.L.L., Ética, Madrid 1958. $1^{\text {a }}$ parte cap. IX-XIV. Para conocer el pensamiento de Sto. Tomás en este punto, cfr. J. LECLERQ, La philosophie morale de Saint Thomas devant la pensée contemporaine. Vrin. Paris 1955, pp. 227 ss.

3. «La Morale... Les directions de l'avenir (DA) Séuil. Paris 1973.

4. «Comment je vois». D.A. p. 207. 
No me propongo discutir - ni justificar, en su caso- el carácter estricto de filósofo de Teilhard ${ }^{5}$. Sólo pretendo exponer a grandes rasgos y en sus puntos esenciales su fenomenología y lo que él denomina su metafísica, como justificación necesaria de su moral, tomada ésta en sentido estricto, es decir, «como un sistema coherente de acción universal (que regule toda la actividad humana) y categórica (en cuanto genera alguna forma de obligación» ${ }^{6}$.

Como he indicado antes, Teilhard de Chardin hace profesión expresa y reiterada de mantenerse al margen de la metafísica en su obra fundamental, Le Phénomène humain - no intenta descubrir entre los elementos del universo «un sistema de relaciones ontológicas y causales» ni establecer en la naturaleza una "conexión de causalidad ontológica», por lo que no debe buscarse en ella una «explicación última de las cosas» ${ }^{7}$ que debe ser leída como una memoria científica, una física o fenomenología, que pretende una «visión coherente y armónica del Universo extendida al hombre». Porque, «la verdadera Física, será aquella que llegue algún día a integrar al hombre total dentro de una representación coherente del mundo». «Establecer, específica, alrededor del hombre, un orden coherente entre consecuentes y antecedentes»; «descubrir entre los elementos del Universo, no ya un sistema de relaciones ontológicas y causales, sino una ley experimental de recurrencia que precise su aparición sucesiva en el curso del tiempo" ${ }^{8}$.

El método con que Teilhard de Chardin emprende esta tarea, que será la conclusión misma de su fenomenología, es la observación. Ver. «Se podría decir que toda la Vida consiste en esto - si no como finalidad, por lo menos sí esencialmente-. Ser más es unirse más: estos serán el resumen y la conclusión misma de esta obra. Sin embargo, lo comprobaremos más aún: la unidad no se engrandece más que por un acrecentamiento de conciencia; es decir, de visión» 9 .

5. No me parece pertinente entrar a discutir aquí el carácter estrictamente fillosófico de la obra teilhardiana, porque nos llevaría lejos, sin, quizás, llevarnos a ninguna parte. Baste reseñar que mientras J. Danielou -y lo recoge y lo hace suyo N. M. Wildiers en la Introducción a $L a$ energía humana - habla de un Teilhard «redescubridor de la metafísica», al modo presocrático, y de una fidelidad fundamental a la escolástica, P.B. Grenet, desde la misma perspectiva, le considera «filósofo a su pesar», deficiente en su conceptuación metafisica (Pierre Teilhard de Chardin ou le philosophe malgré (ui), Seghers, Paris 1961, pp. 5, 13... Tresmontand encuadra su pensamiento en la Filosofia de la Naturaleza (Introducción al pensamiento en Teilhard de Chardin. Taurus, Madrid 1958, p. 8). B. de Solages lo equipara a la física aristotélica y a la cosmología escolástica (Bulletin Litteraire Ecclesiastique, 1947, etc., etc.

6. DA p. 143.

7. Le Phenomene Humain. Seuil, Paris 1955 (PH), p. $21,29$.

8. Le Phenomène Humain $(\mathrm{PH})$ p. 21,54.

9. PH p. 25. 
El objeto de esta visión es el fenómeno. «Sólo el fenómeno, pero también todo el Fenómeno». Que Teilhard no intenta establecer una conexión de causalidad ontológica, lo hemos dicho ya. Pero hay que subrayar también que su fenomenología se basa en la observación de todos los aspectos del fenómeno. En concreto su aspecto externo y el interno. El dedans además del dehors. La complejidad y la conciencia.

Por complejidad no entiende Teilhard de Chardin «la simple agregación, el conjunto desordenado de elementos», sino la «combinación, forma superior de organización que se caracteriza por religar sobre sí un cierto número de elementos»: Pluralidad y organización son los caracteres esenciales. «Heterogeneidad organizada» la define en otro lugar ${ }^{10}$.

Teilhard utiliza el término conciencia en un sentido amplio, para expresar toda forma de psiquismo desde la más diluida en la materia, que nunca es por eso totalmente inerte " «conciencia reflexiva» «conciencia de segundo grado, conciencia al cuadrado o, simplemente, reflexión» ${ }^{12}$.

Este término, «conciencia», ha sido generalizado consciente y voluntariamente por Teilhard, y extrapolado hasta los últimos elementos materiales, en su pretensión de darnos una visión coherente y armónica, unitaria, del Universo, desde el hombre. El principio de unidad de esa visión es la ley de complejidad-conciencia. Así se expresa el propio Teilhard: «La vida no es aparentemente ninguna otra cosa que la exageración privilegiada de una deriva cósmica fundamental (...) que se puede llamar «Ley de complejidad conciencia», y que puede explicarse como sigue: Dejada durante un tiempo bastante largo a sí misma, bajo el juego prolongado y universal de las probabilidades, la materia manifiesta la propiedad de ordenarse en grupos cada vez más complejos, y al mismo tiempo cada vez más subtendidos de conciencia;

10. Cfr. Le groupe zoologique humain (GZH), Seuil, Paris 1956, p. 17. L'avenir de l'homme (AH) Seuil, Paris 1959, p. 137. La Vission du Passé (VP) Seuil, Paris 1975, p. 313.

11. «Porque todo elemento, en un grado más o menos infinitesimal, contiene algún germen de interioridad y de espontaneidad, es decir, de conciencia. Aunque en los corpúsculos más simples esta propiedad permanece imperceptible, como si no existiera». VP. p. 316. En otros lugares habla de «existencia rudimentaria de la psiché en todo corpúsculo» (PH. p. 335) o del «psiquismo oscuro de las primeras células» (PH. 182) o «difuso» en los vegetales (PH. $167 \mathrm{n} .1$ ).

12. Teilhard de Chardin, que aplica el término conciencia a los corpúsculos elementales, aplica al hombre el de interioridad (PH. p. 51). Pero subraya el poder reflexivo del hombre «conciencia al cuadrado» o "de segundo grado», fundamento de todas las propiedades esenciales del hombre: «temible facultad de medir o de criticar la vida», capacidad de prever y planear, libertad, etc. que supone un avance radical y establece una barrera infranqueable entre el animal y el hombre. (Cfr. entre otros: PH 182, VP 106,210,371, AH p. 67,168,205, L'Apparition de l'homme, Seuil, Paris 1956, p. 314-317 etc). Subrayo este «umbral» con el que Teilhard de Chardin, a pesar de la continuidad fenomenológica, manifiesta la discontinuidad ontológica. 
este doble movimiento conjugado de enrollamiento psíquico y de interiorización (o centración psíquica se prosigue, se acelera y se impulsa tan lejos como es posible, una vez comenzado» ${ }^{13}$.

Teilhard habla de una "deriva cósmica», es decir, un proceso evolutivo fundamental dirigido por unas energías «axiales». En una concepción dinámica, la realidad es energía, y esas energías son los ejes conductores del proceso, como el ser es el fundamento de la realidad en una concepción estática. Este "eje de complejidad-conciencia» es parámetro de la evolución en cuanto criterio que permite medir el grado de progreso conseguido en un momento determinado.

Hay, pues, un proceso de crecimiento de la complejidad y de la conciencia, desde lo que Teilhard llama la «nada creable», lo «múltiple puro», «que no es nada y que sin embargo, por virtualidad pasiva de ordenamiento (es decir, de unión, es una posibilidad, una imploración de ser» ${ }^{14}$.

El mundo no es un sistema ya terminado y fijo, en que los elementos aparecen ordenados como un inmenso mosaico, sino «un ensemble qui deroule», un mundo con vida, un inmenso organismo en génesis continua, que a cada instante se renueva y crece. "En nuestro Universo experimental, todo nace, todo se establece y crece por sucesivas fases, todo, incluido el todo" ${ }^{15}$. Es un mundo en cosmogénesis.

Eso quiere decir que entre los elementos de ese todo hay una solidaridad no sólo jurídica sino orgánica, viva. Que en una mirada retrospectiva «cada cosa, por lo más característico suyo, prolonga su estructura, lanza sus raíces en un pasado siempre más lejano. Todo, por alguna extensión muy atenuada de sí mismo, ha comenzado desde los orígenes" ${ }^{16}$. Y, en proyeción hacia el futuro, significa que este mundo no es algo terminado sino un mundo obediente a una evolución irreversible, en crecimiento constante; que su realidad se va haciendo cada vez más compleja y más consciente, más centrada, más unida, más espiritualizada. Que el sentido de esta evolución generalizada es el espíritu, o, utilizando un término que exprese mejor el dinamismo, la espiritualización ${ }^{17}$.

El que haya continuidad no quiere decir homogeneidad absoluta. Teil-

13. AH p. 195.

14. DA p. 209.

15. PH p. 29.

16. PH p. 78. Este enraizamiento en las profundidades del pasado lo ha llamado Paul Grenet «principio de preexistencia larvada» o de «anticipación universal», (o.c., p. 61) y Olivier Rabut "principio filético»: «nada aparece que no haya sido preparado desde siempre». Dialogue avec Teilhard de Chardin. Éd. du Cerf, Paris 1958, p. 37.

17. «... que le Monde exprime, par son Passé, una marche à l'esprit» AH. p. 70. «La Gran- 
hard advierte, y lo subraya, la presencia de «umbrales críticos», puntos de discontinuidad en la evolución, en que aparecen propiedades nuevas, que pueden suponer una transformación ontológica (sobre la que Teilhard no se pronuncia, pero a la que deja abierto el camino, por ejemplo, en la aparición del hombre). Pero sí expresa una dependencia en el orden aparente, no causal, del espíritu respecto a la materia, o más exactamente, una Correspondencia. Espíritu y materia, dedans y dehors, son como las dos caras de una misma realidad. «No hay concretamente materia y espíritu. Sino que existe solamente materia convirtiéndose en espíritu» ${ }^{18}$. No quiere decir que la creciente complejidad material produzca una espiritualización progresiva. Sino que a través de una constante y progresiva organización-complejidad, centración, unión -la materia llega a convertirse - fenoménicamente, vuelvo a repetirlo, y sin olvidar los puntos críticos de la evolución en espíritu. No puede concluirse, por tanto, que el espíritu se reduzca a la materia. Sólo que la aparición del espíritu exige una determinada estructuración de la materia. Y que ésta, por consiguiente, sería como una cara de la realidad, de la que la otra sería el espíritu.

¿Cómo ha conseguido Teilhard de Chardin esta visión en cosmogénesis? Está indicado más arriba, al enunciar su objetivo: una visión coherente del Universo desde el hombre. Es la «posición singular, sobre un mundo, que domina la fracción entera del cosmos actualmente abierta a nuestra experiencia», del hombre, "centro de perspectiva» lo que aprovecha Teilhard. Proyecta su mirada, su observación sobre el pasado - «La visión del pasado» es el título de una de sus obras - y descubre, hasta donde es posible la visión, una degradación progresiva en la complejidad, que se corresponde con una disminución de la conciencia que hace del hombre meta y «clave del Universo». En virtud de esta visión, Teilhard extrapola, más allá de lo observable y sin «que pretenda descubrirlas como fueron realmente» ${ }^{19}$, hasta los primeros orígenes de ese Universo. Hasta adivinar ese «múltiple puro», que implora el ser, es decir la unión, la centración, la complejidad y la conciencia rudimentaria o infinitesimal (que son como las dos caras de esa realidad que, en su proceso de crecimiento, culminará en el hombre). Fruto de un esfuerzo específico y total de la tierra, el hombre aparece en esa perspectiva como el término de una inmensa operación de desarrollo que parece ligada con la historia más profunda de la tierra. La materia matriz del espíritu. Y el hombre «meta»o «clave» de la evolución ${ }^{20}$. Pero meta transitoria, porque la evolución conti-

de Option». Que la vida corre hacia el «ser mejor» y sobre todo, hacia el ser más, más fuertes y más conscientes. La Vission du Passé (VP) Seuil, Paris 1957, p. 103.

18. L'energie humaine (EH) Seuil, Paris 1962, p. 74.

19. PH p. 29.

20. ... en el espiritu humano, como en un fruto único e irreemplazable, se encuentra reuni- 
núa, sustentada ahora por el hombre quien, consciente y libremente, debe asumirla para llevarla hasta el fin. Por eso el hombre es al mismo tiempo que meta y clave, «flecha» o «yema» de la evolución, "centro de construcción del Universo" ${ }^{21}$. El sentido de la evolución es, pues, el mismo, puesto que se trata de un único movimiento: con diversas fases (biosfera, noosfera) hacia el espíritu. Pero, alcanzado ya, al parecer, el término a nivel de individuo con el «Paso de la reflexión» ${ }^{22}$, la espiritualización futura se traduce en la formación de una superconciencia en el plano del psiquismo y una organización cada vez más compleja. En esta tarea que se le confía al hombre, éste dispone de la misma «energía» que agrupaba los primeros corpúsculos, de su misma fuerza o poder de unión: el amor. Un amor que, en definitiva, y sin entrar en detalles, salva al individuo humano de la despersonalización que le amenaza en la asociación con los demás hombres, como dice Teilhard en la "planetización», a la que debe tender ${ }^{23}$. Porque la unión - por amor, por donación de sídiferencia ${ }^{24}$, da plenitud a los seres al unirlos.

La extrapolación de Teilhard en su descenso hacia el pasado llega, en ese proceso de descentración, de desunión, de descomplejificación y desconcienciación hasta el «múltiple puro» - lo absolutamente desunido- y se proyecta en el futuro hasta esa superconciencia universal, especie de conciencia colectiva que alcanzará la humanidad en su estadio ultra-humano (el de la humanización de la humanidad). Más allá, en el principio y en el fin, está «ese misterioso centro de nuestros centros que yo he llamado Omega» ${ }^{25}$.

dã toda la vida sublimada, es decir, todo el valor cósmico de la tierra». "L'esprit de la Terre». EH, p. 35.

21. PH, p. 27, 249 «L'esprit de la Terre», p. 15 VP 320.

22. Este punto lo desarrolla Teilhard de Chardin en «El grupo sociológico humano» p. 100. Véase un texto citado por $C$. Cuénot: «Hasta el hombre, se puede decir que la naturalezà trabajaba en fabricar «la unidad o grano de pensamiento», ahora parece que estamos decididamente lanzados hacia «edificios de granos de pensamiento», siguiendo las leyes de alguna hiperquímica gigantesca, cada vez más hacia arriba en el abismo de lo infinitamente complejo». Teilhard de Chardin, Ed. Labor, Barcelona 1966, p. 83.

23. AH. p. 167: Teilhard habla del amor - como de la conciencia- en sentido amplio, "como afinidad del ser por el ser», PH. 293-294.

24. PH. 291, L'energie humaine.

25. $\mathrm{PH} \mathrm{300.} \mathrm{«En} \mathrm{el} \mathrm{sistema} \mathrm{cuya} \mathrm{lógica} \mathrm{hemos} \mathrm{adoptado,} \mathrm{la} \mathrm{humanidad} \mathrm{no} \mathrm{es} \mathrm{el} \mathrm{término} \mathrm{del}$ cosmos, porque todavía es múltiple. Esto quiere decir que por el sólo hecho de que la evolución atraviesa, sin detenerse en ella, a la persona humana, nos vemos forzados a trasladar infinitamente hacia adelante el término de movimiento que nos arrastra... Henos aquí... arrojados al océano de un porvenir inmenso, en el que no hay descanso posible antes de la aparición de un centro único de la noosfera» (EH p. 82-83). Un centro personal (y supremamente) personalizante, en la que la ciencia - centración- alcanza valores supremos en la consumación del universo entero. «Así, pues, la extrapolación de la trayectoria que sigue el mundo sólo puede conducirnos, a partir del corpúsculo humano, al estadio final de una personalidad del universò) (EH. p. 84). 
Esta es, a grandes rasgos, la «Weltanschauung», la metafísica en sentido amplio ${ }^{26}$, que Teilhard «ve», a la que «se adhiere» (Cfr DA p. 143) y que genera una moral, no como algo distinto de ella, sino como el aspecto práctico de un mismo sistema del que la metafísica - en sentido amplio- es la cara teórica. Por eso Teilhard no la incluye entre sus convicciones intelectuales, entre «lo que ve» - fiel a su método-, como algo distinto de su fenomenología. Sólo ésta, la metafísica y la mística resumen sus puntos de vista sobre el mundo y Dios ${ }^{27}$.

Y por eso mismo Teilhard no presenta esa moral como un sistema, sino como las consecuencias prácticas que sirven de test de validación de la fenomenología ${ }^{28}$.

Las pocas páginas que Teilhard dedicó al tema - espaciadas además en el tiempo, desde 1926 en que escribió las primeras hasta 1945, fecha de su último trabajo - las coloca al final de la exposición teórica de su fenomenología. Pero tienen la importancia de ser la prueba de fuego de la aplicación de esas visiones a la actuación del hombre, que es para él -ya lo hemos dicho- el centro de perspectiva desde el que contempla el universo. Este carácter de «validación» de la moral respecto de la metafísica se lo impusieron a Teilhard las acusaciones de ateísmo e inmoralidad que se formularon al evolucionismo en general y al transformismo en particular. La enemiga de fondo de la evolución eran, pues, sus consecuencias religiosas y morales. El evolucionismo comprometía la actividad humana y defendía una doctrina presidida por el egoísmo y la brutalidad. «Es, pues, una escuela de inmoralidad que en nombre de la selección natural, legitima y enseña la lucha egoísta y la prioridad de la fuerza sobre el derecho» ${ }^{29}$. Así se expresaba en 1926 . Y en 1930 recoge los ataques de materialista, de «anticristiano», corruptor y responsable de todos los males existentes.

26. Reflexionando sobre esta fenomenología, Teilhard encuentra que el progreso en la complejidad de la materia y en el enrollamiento psíquico -progreso en la unión- es un progreso en el ser. Por lo que llega - "genética, si no ontológicamente»- a un concepto de ser «que consiste en un movimiento de unión». "Ser es unirse a sí mismo o unir a los otros (forma activa). Ser es ser unido o unificado por otro (forma pasiva)».

A partir de esta noción de ser, Dios, si es, ha de ser también unión, el ser que, en cuanto autosubsiste se unifica a sí mismo. Por eso, «es necesario que nos lo representemos como oponiéndose trinitariamente a sí mismo». Y sólo existe plenamente uniendo. «Por el hecho mismo de que se unifica sobre sí para existir, el Ser primero hace ipso facto brotar otra especie de oposición no en el corazón, sino en sus propias antípodas. La Unidad auto-subsiste, en el polo del ser; y necesariamente, como consecuencia, todo alrededor, en la periferia, lo Múltiple: lo Múltiple puro (entendámonos bien) o nada creable, que no es nada («absolue multiplicité est synonime de néant», dice también en «Mon Univers») y sin embargo, por virtualidad pasiva de agregación de ser». De aquí el concepto de unión creadora o de creación unitiva.

27. DA p. 207-211.

28. «El test de una metafísica, es la moral que deriva de ella». DA... p. 145.

29. VP p. 183-184, 190-191. 
Todas estas dificultades desaparecen y las acusaciones se convierten en argumentos cuando se clarifica la esencia, se precisa el verdadero contenido y se comprende el sentido auténtico de la evolución y del transformismo.

La evolución no es más que el resultado del descubrimiento del tiempo como elemento constitutivo de las cosas. «Para nosotros, dice Teilhard, la duración impregna ahora, hasta sus últimas fibras la esencia de los seres. Penetra hasta la materia misma; no es que por ello las cosas se conviertan (como se ha prentendido a veces) en inconsistentes y móviles, sino en el sentido de que aparecen hoy como interminables, indefinidas, en la preparación, la maduración y la consumación de su naturaleza, por inmutable que ésta se suponga» ${ }^{30}$. En el fondo, «el transformismo, ¿qué otra cosa es sino la creencia en un lazo natural entre las especies animales?». «Ser transformista no es sino admitir simplemente que podemos hacer la historia de la vida» ${ }^{31}$, como un caso particular de la historia universal entendida como una historia natural del mundo».

Esto, y nada más que esto significa ser evolucionista o transformista. Después, pero no antes ni por el hecho de ser evolucionista, se puede ser materialista o espiritualista; como se puede explicar el transformismo al modo lamarckiano o darwinista, o teilhardiano. Trilhard observa, ve -en el mundo de los fenómenos al alcance de su mirada - que esa historia es la historia de un progreso hacia el espíritu, y que este es por tanto, el sentido del transformismo y de la evolución en general. Y no admite las explicaciones de Darwin y Lamarck, la selección natural o la adaptación al medio, ni las más simples del mecanismo haeckeliano. Serían materialistas, corruptoras de «la moral», quebrantarían el entusiasmo y serían simplemente inmorales, estas interpretaciones del transformismo. La concepción de un mundo que se mueve a espaldas o a contrapelo de la libertad y del esfuerzo humano, invita al desinterés y a la pereza; la selección natural o la adaptación al medio, conducen a la lucha egoista y a la prioridad de la fuerza sobre el derecho ${ }^{32}$. Pero no la evolución y el transformismo en sí mismos, en su esencia, y menos la interpretación teilhardiana: ortogenética, finalista y espiritualista — que son una «auténtica escuela de moralidad y espiritualización», o, como dice en otro lugar, de esperanza, de caridad y de esfuerzo ${ }^{33}$.

30. VP, p. 179-181.

31. VP, p. 124,214 .

32. Quiero subrayar que Teilhard expresạ su intención expresa de no entrar en si esas «consideraciones simplistas» expresan correctamento «las ideas del gran científico que fue Darwin», VP. 191. Sólo las toma como punto de partida para sus consideraciones morales.

33. VP. p. 186,223 . 
Teilhard denomina a su moral «dinámica» frente a la «estática», como derivadas de concepciones del mundo contrapuestas, en movimiento y en equilibrio. Y subraya las ventajas de esa moral dinámica.

La concepción de un mundo en equilibrio contempla un mundo terminado, en que los seres, ordenados o no jerárquicamente, están distribuidos en el espacio, físicamente yuxtapuestos, con coexistencia meramente accidental pero temporal y ónticamente insolidarios. "Cada hombre en este mundo estático representaba en el mundo una especie de término absoluto, cuya existencia se trataba de proteger contra toda invasión exterior ${ }^{34}$. Término absoluto quiere decir que en él se acaba -en cuanto límite y en cuanto perfección- el mundo; que el hombre es, por tanto, el ser perfecto y perfectamente independiente. Que no necesita nada; sino que no le quite lo que es suyo, es decir, que se defiendan sus derechos. Pero también significa que es un ser naturalmente aislado, con relaciones que no afectan a su ser, sino puramente extrínsecas, establecidas más que para unir para subrayar y defender las diferencias. Esta concepción insiste en la individualidad de la persona. Peligra la personalidad cuando se invanden los límites de la individualidad. «El hombre, por el hecho mismo de individualizarse, parece convertirse en incomunicable e incomprensible para los demás hombres que le rodean. Y entonces no puede ver otra salida para la necesidad de comunión universal, que a pesar de todo le trabaja, que la vuelta atrás y la re-inmersión consciente en la multitud» ${ }^{35}$.

Y esta es, precisamente, dice Teilhard, la concepción del mundo vigente hoy. «Hasta donde es posible dominar las tendencias psicológicas de nuestro tiempo, se tiene la impresión de que atravesamos por una fase crítica de individualismo. Nunca, sin duda, en ningún momento de la historia, ha sido más general que hoy, en todos los grupos sociales, un sentido más agudo de los derechos de cada elemento. Derechos del hombre, derechos del ciudadano, derechos del trabajador, derechos de los pueblos a actuar, a pensar, a desarrollarse libremente..., todo ello se ha exaltado en las conciencias personales y en las colectivas. Nada nos ha llegado a ser más odioso que la idea de una intrusión exterior injustificada en nuestro poder de juzgar (autónomo)... representa... un progreso en la constitución de unidades pensantes en medio del universo. Pero... en la humanidad actual, el exceso de individualismo amenazara con producir el desmigajamiento, la dispersión y, en consecuencia, el retorno a la multitud y la materia. Cada uno tiende a no ocuparse del bien común. Las agrupaciones más naturales se disgregan. La certezas, lentamente concentradas mediante ensayos y reflexiones seculares, se evaporan. El ideal de la acritud moral viene a ser cierta independencia rebelde ${ }^{36}$.

34. EH p. 132.

35. EH p. 78.

36. VP. p. 194-195. 
Individualismo, independencia, dispersión, multitud, relaciones puramente externas entre seres extraños, que defienden, con egoísmo, los derechos del individuo: relaciones jurídicas. No hay razones intrínsecas - no hay que olvidar que estamos hablando desde una perspectiva natural - que obliguen al hombre a interesarse por los otros seres, que en un mundo estático le son ajenos; ni por el todo, que no existe en sí sino que sólo es un ente de razón, no un ser físico; ni por el bien común, puesto que no hay una verdadera comunidad sino sólo un agregado de elementos yuxtapuestos, una multitud.

Teilhard califica la moral resultante de esta concepción del universo como individualista y egoísta, como una moral negativa y «a la defensiva», en cuanto orientada a salvaguardar los derechos del individuo ${ }^{37}$. Como una moral convencional, en cuanto resultado, no de una necesidad natural, sino de un acuerdo de no quebrantar el orden social establecido sobre el equilibrio de esos derechos. Equilibrio que se mantiene más fácilmente por la represión de la energía y la limitación de la fuerza. «La moral ha nacido ampliamente como una defensa empírica del individuo y de la sociedad. Desde que seres inteligentes han empezado a encontrarse en contacto, $y$ en consecuencia en fricción, han sentido la necesidad de guardarse contra sus mutuas usurpaciones. $\mathrm{Y}$ desde que se ha encontrado, con el uso, una organización que garantizase casi a cada uno lo que le era debido, este mismo sistema ha experimentado la necesidad de garantizarse contra cambios que vendrán a remover de nuevo las soluciones admitidas y a quebrantar el orden social establecido. La moral ha sido comprendida principalmente hasta aquí como un sistema fijo de derechos $\mathrm{y}$ de deberes que intenta establecer entre individuos un equilibrio estático y que se preocupa de mantener éste por medio de una limitación de las energías; es decir, de la fuerza» $(\mathrm{EH}){ }^{38}$. Por eso Teilhard llama a este moralista «jurista» y «equilibrista».

Una moral, por fin, en la que «la obligación es frecuentemente comprendida por los espíritus que hemos llamado «jurídicos», como una obediencia debida al orden más o menos extrínseco y fantansioso de un amo»" ${ }^{39}$.

37. En 1947, un año y medio antes de la proclamación de los derechos del hombre y refiriéndose a la de 1789 escribe Teilhard: «En su expresión primera de 1789, los Derechos del hombre fueron principalmente la manifestación de una voluntad de autonomía absoluta: Todo para un individuo en el seno de la sociedad» (AH p. 247). No es que Teilhard pretenda subordinar aquél a ésta, como en cualquier totalitarismo al uso - exalta incluso la «singularidad incomunicable del ser que poseemos»- sino destacar el carácter egoísta, por individualista, de la insistencia en los derechos individuales. Quizá porque, como ha señalado L.E. PALACIOS, se consideran los derechos humanos fundados en la persona, que cierra e incomunica, y no en la naturaleza, que es vocación por el bien común. («La persona humana» en La Filosofía en el BUP. Madrid 1977, p. 494). Teilhard entiende que la personalidad no disminuye sino que se perfecciona al comunicarse, en la donación que hace de sí misma a otro ser en el amor. Cfr. nota 54.

38. EH, p. 131-132.

39. Science et Christ. p. 81 . 
La moral dinámica, tal como la ve Teilhard, está entroncada en el proceso general del universo, como el aspecto práctico del transformismo. En una concepción dinámica, el hombre aparece como meta y flecha de la evolución. En cuanto término recoge en su espíritu, como «fruto único e irreemplazable» toda la savia de la vida y toda la energía de la materia. «Eso quiere decir que la moral no es nada menos que el término superior de la mecánica y de la biología». Pero, meta transitoria, el hombre es «centro de construcción del universo» que debe cargar con «el peso terrible de la evolución», y así, «el mundo se construye finalmente por potencias morales, y la moral, recíprocamente tiene por función construir el mundo. Toda una apreciación nueva, que conduce a un programa nuevo de la moralidad $\gg{ }^{40}$.

¿En qué consiste esta novedad?

En primer lugar, la moral deja de ser algo postizo y artificial, consecuencia de una experiencia de invasión mutua de derechos, resultado de un acuerdo exigido por la necesidad de mantener un orden externo a los seres mismos para convertirse en el fruto natural, como el hombre mismo, en el fruto genético de un pasado que se remonta hasta los comienzos del mundo y que, al llegar al hombre se condensa en valores morales, propuestos al mismo por la necesidad interna del crecimiento y libremente asumidos por éste. La moral se integra en el conjunto del proceso, y la acción, con el paso de la reflexión, se hace consciente, libre y moral. «El cosmos se construye físicamente, a partir del hombre, por magnitudes morales.... No hay alrededor de nosotros un ámbito físico y un ámbito moral. No hay sino el físico moral» ${ }^{41}$.

No es que la moral se confunda con lo físico, sino que, como la materia se convierte en, no es, Espíritu, o «como la libertad no es sino la expresión avanzada y distinta de lo que se disimula o se disocia en los determinismos psíquicos», la discontinuidad en la continuidad del proceso hace que las energías físicas lleguen a ser potencias morales. Y que la obligación sea una necesidad moral.

Teilhard se inscribe en la corriente que desde Kant insiste en la obligación como nota esencial de la moral. «Una moral en sentido estricto es un sistema coherente de acción universal (que regula toda la actividad humana) y categórica (que incluye alguna forma de obligación)» ${ }^{42}$.

Para que haya obligación, dice Maritain debe darse una especie de coerción interna, o de lazo, absolutamente indestructible y que se vincula con la libertad misma. «Se trata de una coerción ejercida por el intelecto sobre el libre

40. EH, p. 131. Cfr. también ib. p. 35.

41. EH, p. 90. Los primeros subrayados son míos, G.G.A.

42. DA p. 143. 
albedríô». Es el sentimiento de estar ligado por lo bien que veo» ${ }^{43}$. Es coacción sin determinismo, una fuerza que se impone respetando la libertad. ¿Cómo? En forma de valor aceptado, querido libremente. Lo característico del deber, dice Zubiri, no es tanto ser imperante como ser apropiado.

Pues bien, esta es la obligación de la moral dinámica teilhardiana. El hombre, centro de perspectiva, descubre una ley de progreso en el pasado prehumano. Que es, que debe ser más bien, la misma ley de progreso de la esfera humana del pensamiento - la noosfera-. Que lo sea depende de la libre aceptación del hombre de esa «terrible carga de la evolución». Pero el hecho de que sea un único proceso de desarrollo, aunque consciente y libre en el nivel humano, da a la moral un carácter de inmanencia, de naturalidad. La exigencia de continuidad explica la coacción, quasi-física, en cuanto radicada en las esferas de los determinismos material y biológico. Pero en definitiva, la obligación es una exigencia racional, en cuanto es el pensamiento el que ve el progreso espiritual que se le ofrece y lo quiere. «El fundamento inicial de la obligación para el elemento humano es el hecho de haber nacido y de desarrollarse en función de una corriente cósmica. Debemos actuar y de una manera determinada, porque nuestros destinos individuales están ligados a un destino universal. El deber no es otra cosa en su origen, que el reflejo del universo en el átomo» ${ }^{44}$.

El destino individual de cada hombre ligado al destino universal. He ahí el lazo de que habla Maritain. Pero es un lazo que debe establecer definitivamente la libertad humana. «La finalidad de esta nota no es demostrar que hay un progreso necesario, infalible; quiero dejar sentado tan sólo que, para el conjunto de la humanidad, existe un progreso ofrecido, esperado, análogo al que los individuos no pueden rechazar sin pecado y sin condenación» ${ }^{45}$.

Es, pues, una moral de la obligación, fundada ésta en una exigencia de la razón, como en Kant, pero no puramente formal, sino asentada sobre el valor de un progreso singular y humano (la humanización de la humanidad que, según Teilhard, no sólo no despersonaliza sino que superpersonaliza: la unión diferencia) libremente asumido por el hombre como tarea propia.

La obligación no es la consecuencia de una orden venida desde fuera, sino de una constricción interna, inmanente. «Ha pasdo el tiempo en que Dios podría imponerse a nosotros desde fuera, simplemente, como un señor o un propretario. El mundo no se arrodillará en adelante más que ante el Centro

43. Las nociones preliminares de la filosofía moral. Club de Lectores. Buenos Aires 1966, p. 190.

44. EH. p. 36.

45. AH p. 31 , nota 1 . 
Orgánico de su evolución» ${ }^{46}$. Pero es que ese Centro es. Omega, «Dios de síntesis cósmica en el que pudiéramos tener conciencia de progresar y reunirnos por trasnformación espiritual de todas las potencias de la materia» ${ }^{47}$, término de ese crecimiento espiritual. «En la moral de movimiento... que sólo se define por relación a un estado u objeto a alcanzar: es indispensable que éste término aparezca con una claridad suficiente para ser deseado y aspirar a él».... «Una moral de equilibrio - que puede constituirse y subsistir cerrada sobre sí misma, puesto que pretende sólo ajustar unos a otros los elementos asociados, puede ser, lógicamente, agnóstica y estar absorbida por la posesión del instante presente. Una moral de movimiento está, necesariamente, inclinada sobre el futuro, en la persecución de un Dios». Un Dios que, con su fuerza de atracción, sea capaz de despertar y sostener ese proceso de desarrollo hacia el espíritu, «Dios supremanente personal, del que nos distingamos tanto más, cuanto más nos perdamos en Él» ${ }^{48}$.

De esta forma la moral dinámica, enraizada en la materia y en la vida, pende en último término de Dios como una llamada y una aspiración. Pero no son como en Bergson dos las fuentes de la moralidad, la coacción social y la fuerza de aspiración, sino una sola, resultado de un único movimiento de desarrollo aspiración. "Cuando cada hombre, en virtud de una concepción del mundo... admite que su verdadero ser no se halla limitado a los contornos estrechos de sus miembros y de su existencia histórica, sino que, en cierto modc, forma cuerpo y alma con el proceso que arrastra consigo al universo, entonces comprenderá que, para permanecer fiel a sí mismo, debe entregarse como a una obra personal y sagrada, al trabajo que le pide la Vida. En él renacerá la confianza en el mundo cuya totalidad no podrá perecer; y además la fe en un Centro Supremo de personalización, de reunión y cohesión, sólo en el cual puede concebirse una salvación del universo" (VPc 175).

Por eso Teilhard, en un esfuerzo de síntesis de las divergencias bergsonianas, exclama: «L'erreur de Bergson! Les deux sources! Phenomenalement une seule!». Como ha estudiado M. Barthelemy-Madaule, Bergson y Teilhard, a pesar de su profunda coincidencia en la herencia darwiniana, en la concepción evolutiva y en el proyecto de dar al progreso, a la ciencia y a la técnica una significación espiritual, el método, la realización y la conclusión divergen. Frente al pensamiento analítico de Bergson que concluye en la divergencia de ciencia, filosofía y religión, Teilhard ha intentado superar esa divergencia por la síntesis $\mathrm{y}$, al final, la convergencia de las mismas ${ }^{49}$. En resumen: Moral físico-

46. EH. p. 136.

47. EH. p. 136.

48. EH. p. 135 .

49. Cfr. M. Barthelemy-Madanle. Bergson et Teilhard de Chardin. Seuil, Paris 1963, en especial pp. 632-641. Para el juicio de Teilhard sobre «les deux sources»... Cfr. pp. 494 ss. 
biológica - si cabe hablar así-, en cuya necesidad se enraiza, se proyecta y salta hasta la trascendencia de la que depende y a la que aspira. En un único proceso engloba materia, hombre y Dios; el hombre como centro de perspectiva y de construcción, como meta y flecha de la evolución. La libertad humana, que enraiza en las oscuridades de la necesidad, y que siente por eso la constricción de una obligación moral, se abre a la claridad absoluta y a la llamada divina que transfiguran el peso de la obligación en la atracción del ideal.

Propóngasele al hombre, dice, «la visión de un universo organizado, en el que todas las partes se hallan físicamente ligadas entre sí, en su aparición y en su destino... y verá exaltarse casi hasta el infinito, la magnitud de sus responsabilidades. Él, que hasta entonces podía creerse en la naturaleza como un ser de paso, local, accidental, libre de malgastar, a su costa individual, la chispa de la vida que le cupo en suerte, descubre de pronto, en el fondo de sí mismo la carga terrible de conservar, de acrecentar, de trasmitir la fortuna de un mundo. Su vida, en un sentido, ha dejado de ser cosa particular suya. En cuerpo y alma, emerge de un trabajo creador al que ha colaborado desde siempre la totalidad de las cosas; y si él se sustrae a la tarea asignada, algo de este esfuerzo se perderá para siempre y faltará ya para todo el futuro... En una parte infima, pero real, el éxito de la enorme empresa, del inmenso alumbramiento universal está en las manos del menor de entre nosotros... Sus ojos se han hecho más sensibles a la grandeza del universo; $y$, al mismo tiempo, su corazón se ha abierto sin esfuerzo al soplo de la caridad» ${ }^{50}$.

Con estas palabras pasamos a otro aspecto de esta moral dinámica: el de la superación del individualismo por la solidaridad física y la conversión del egoísmo en caridad. Todas las partes, dice Teilhard, aparecen ligadas en su aparición y en su destino. Por esa comunión de origen, las relaciones entre los seres, entre los hombres, se convierten de jurídicas y nominales en orgánicas y naturales. Por la unidad de destino - la humanización de la humanidad- el egoísmo y el desinterés del hombre, constituido en término absoluto, se transforma en caridad y entusiasmo. Y la moral deja de ser ese equilibrio de fuerzas, pulso de derechos y deberes, para convertirse en reunión de energías en orden a la construcción del gran edificio del universo y a la formación de ese «super-individuo».

Teilhard subraya el carácter solidario de la actuación humana en su enraizamiento y en su finalidad frente a una concepción que insiste en el individualismo. No porque niegue la singularidad incomunicable de la persona o la minusvalore: «En el hombre, dice, a través de un punto crítico, la primera aparición de la unidad, de la molécula personal acabada» ${ }^{5 !}$. Sino porque la insis-

50. VP, pp. 191-192. Cfr. también pp. 222-223.

51. EH. p. 77 . El subrayado es mio, G.G.A. 
tencia en ella conduce al egoísmo. Y «es el egoísmo el que endurece y neutraliza la materia humana. La unión diferencia» ${ }^{52}$. El individuo humano es persona cabal. Pero es sólo el primer fruto de la unión, de la convergencia de las energías de la vida. Es preciso prolongar ese proceso de centración que ha culminado en la «hominización de la vida» hasta «la humanización de la humanidad ${ }^{53}$. Y ese proceso no puede continuarse sino en la ruptura del caparazón de la individualidad que le aísla de los otros hombres. «El hombre evita comunicarse con otro hombre porque teme disminuir su personalidad al compartirse. Intenta crecer aislándose. Pues bien, si el universo es orgánicamente posible... lo contrario es lo verdadero. El don que hacemos de nuestro ser, lejos de amenazar nuestro yo, debe tener por efecto perfeccionarlo». ${ }^{54}$. Esa ruptura se consuma en el amor: del hombre a la mujer en la pareja, del hombre a los hombres en la sociedad, y del hombre al Todo en el universo. Por eso puede decir Teilhard que el evolucionista es «aquel cuyo corazón se ha abierto sin esfuerzo al soplo de la caridad» y que es «el amor el que construye físicamente el universois ${ }^{55}$.

Empresä grande, capaz de enhebrar los espíritus, la moral se ofrece como una tarea constructiva. Teilhard ha sabido comprender y valorar la presentación positiva, y no restrictiva y hecha de prohibicionismos, de su espiritualidad y de su moral. No se trata de una ascética de renunciación, de limitación de las energías - «he ahí el pecado» exclama Teilhard ${ }^{56}$-, sino una moral de ideal, del esfuerzo y de la esperanza. Ideal de crecimiento del ser, es decir de la conciencia y de la libertad.

Los principios de esta moral de movimiento, que podrían resumirse en uno solo: hacia el espíritu, y que «definen el valor de los actos humanos», son:

1. Es bueno sólo lo que contribuye al crecimiento del Espíritu sobre la Tierra.

2. Es bueno, al menos fundamental y parcialmente, todo lo que proporcione un crecimiento espiritual de la tierra.

3. Por fin, es lo mejor lo que asegura su más alto desarrollo a las potencias espirituales de la Tierra» ${ }^{57}$.

Después de proponer algunos ejemplos - la moral de dinero ya no debe

52. Ib., p. 80 .

53. AH. p. 19.

54. EH. p. 80.

55. EH. p. 90. VP, p. 222-223.

56. EH. p. 134. Recuérdese cómo Teilhard encuentra el valor pósitivo hasta en nuestras «pasividades de disminución» (dolores, sufimientos, etc.), en una mayor disponibilidad para la acción divina. Cfr. «Le Milieu divin», p. 81-82.

57. EH. p. 132-136. 
estar presidida por la idea de justicia como equilibrio- «a tanto, tanto», - sino por la potenciación o no del espíricu por la riqueza; la moral del amor, subordinada antes a la procreación, descuidaba el valor espirituaizador del amor mismo- en que se concreta esa moral de conquista y edificación frente a la moral estática, a lá defensiva, orientada a proteger y sostener, concluye Teilhard, «Sólo la iđẹa de un cosmos en movimiento hacia lo personal parece capaz de sostener y de canalizar hacia el futuro las energías presentes en la humanidad. Si hay un hecho patente hoy es la impotencia, para las morales de equilibrio, de gobernar la tierra. Los sabios se esfuerzan vanamente en mantener el orden social e internacional, limitando la fuerza. Por la lógica misma de la vida, la fuerza nace irrésistiblemente por todas partes, bajo nuestros pies y entre nuestras manos, y exige imperiosamente crecer hasta el fin de sí misma. Nuestro mundo ha entrado en la era de la fuerza, al mismo tiempo que se despertaba a la conciencia de su evolución. Se romperá sobre sí mismo si no descubre una salida donde hacer converger su exceso de potencia hacia arriba y hacia adelante. No obedecerá más que a una moral de movimiento; y no concibo posible tal moral fuera de la fe en la existencia de una transformación que hace pasar el universo del estado material al espiritual» ${ }^{58}$.

Así cumple a la evolución ser «escuela de moralidad y de espiritualización» y Teilhard, que se reconocía hijo de la tierra por temperamento y vocación, puede dominarse también hijo del cielo por educación y formación" ${ }^{59}$.

Gaspar GARCÍA ABRIL

58. EH. p. 138-139.

59. Le coeur de la matière (inédito). 